\title{
Capacitação de Gestores em Programa de Prevenção da Violência Comunitária ${ }^{\star}$
}

\author{
Anelise Lopes Rodrigues, ${ }^{\star}$ Jorge Castellá Sarriera \\ Universidade Federal do Rio Grande do Sul, Porto Alegre, RS, Brasil
}

\begin{abstract}
Resumo
A dificuldade em aliar teoria à prática tem sido preocupação constante entre estudantes e profissionais que atuam em políticas sociais. Nesse trabalho serão abordados aspectos teórico-metodológicos da psicologia comunitária que subsidiaram o processo de capacitação de uma equipe gestores no âmbito do Programa de Prevenção da Violência do Estado do Rio Grande do Sul (em parceria com a UNESCO), com vistas à realização de um Diagnostico Situacional numa comunidade socialmente vulnerável. Os encontros de capacitação propiciaram aos gestores um espaço de reflexão, contribuindo para a construção de um olhar mais crítico e menos estigmatizado acerca do problema da violência.
\end{abstract}

Palavras-chave: psicologia comunitária; políticas sociais; violência; políticas públicas.

\section{Training of Managers in a Community Violence Prevention Program}

\begin{abstract}
The difficulty to link theory to practice has been constant concern between students and professionals who work in social policies. In this paper will be addressed theoretical and methodological aspects of psychology community which supported the training of a team managers of the Violence Prevention Program in the State of Rio Grande do Sul (developed in partnership with UNESCO), with a view to achieving a situational diagnosis in a community socially vulnerable. The training provided to managers a space of reflection, contributing to the building of a more critical eye and less stigmatized about the problem of violence.
\end{abstract}

Keywords: psychology community; social policies; violence; public policies.

\section{Psicologia Comunitária e Políticas Sociais}

As políticas sociais voltadas ao enfrentamento das desigualdades sociais, pobreza e vulnerabilidade vêm passando por transformações significativas no Brasil. Especialmente na última década, uma quantidade expressiva de programas e projetos sociais vem sendo desenvolvidos no intuito de prevenir, combater ou ao menos minimizar os efeitos de problemas sociais como a pobreza, violência, miséria, discriminação, entre outros. Diante desse panorama, observa-se uma crescente inserção de profissionais das áreas da saúde, ciências humanas e sociais no âmbito de programas e projetos voltados ao desenvolvimento social e comunitário. Também no que se refere à psicologia, de modo peculiar, percebe-se a cada ano maior inserção de profissionais e acadêmicos (em situação de estágio) no campo das políticas públicas e sociais, ensejando assim uma atuação cada vez mais comprometida com a transformação social.

Nas disciplinas e cursos relativos à Psicologia Comunitária que temos desenvolvido nos últimos anos na Universidade, ${ }^{1}$ seja em nível de graduação, extensão ou

\footnotetext{
* "Artigo elaborado a partir do trabalho de consultoria técnica realizada no Contexto da Cooperação UNESCO (Organização das Nações Unidas para a Educação, a Ciência e a Cultura - acrônimo de United Nations Educational, Scientific and Cultural Organization) / Secretaria Estadual de Saúde do Rio Grande do Sul, Programa de Prevenção da Violência (914BRA3043). As opiniões aqui expressas são de responsabilidade dos autores e não refletem necessariamente a visão da UNESCO sobre o assunto".

$\star \star$ Endereço para correspondência: Universidade Federal do Rio Grande do Sul, Instituto de Psicologia - Programa de Pós Graduação em Psicologia. Rua Ramiro Barcelos, 2600 - Santa Cecília. CEP: 90035003 - Porto Alegre, RS Brasil.E-mail: aneliselr@hotmail.com, jorgesarriera@gmail.com

O Grupo de Pesquisa em Psicologia Comunitária da Universidade Federa do Rio Grande do Sul(GPPC-UFRGS) é responsável pelas disciplinas de Psicologia Comunitária, Desenvolvimento e Intervenção Psicossocial em nível de graduação, bem como da disciplina Programas Sociais e Intervenção Psicossocial no Programa de Pós-Graduação. Além disso, tem desenvolvido nos últimos anos diversos cursos de extensão abertos à comunidade em temáticas correlatas à Psicologia Comunitária, tais como "Saúde Comunitária", "Intervenção Psicossocial" e "Projetos Sociais".
}

especialização, observa-se um crescente interesse por parte de alunos e profissionais nas temáticas referentes à Intervenção Psicossocial e Saúde Comunitária, temáticas que até pouco tempo eram relegadas a um segundo plano pelos estudantes de Psicologia. Também profissionais e acadêmicos de outras áreas como Serviço Social, Enfermagem, Medicina, ou de um modo geral, aquelas ligadas às políticas públicas e Terceiro Setor, demonstram interesse semelhante e têm buscado - por meio de cursos de extensão universitária - adquirir ou aprimorar conhecimentos de caráter teórico-prático no intuito de atender demandas exigidas em Centros de Atendimento Psicossocial (CAPS), Centros de Referência da Assistência Social (CRAS), Estratégias de Saúde da Família (ESF), Unidades Básicas de Saúde (UBS), entre outros serviços voltados à saúde, desenvolvimento social e comunitário.

Nas experiências em sala de aula, além da ânsia e urgência demonstrada pelos estudantes na aquisição dos novos conhecimentos, uma espécie de apreensão tem sido notória a partir do seguinte questionamento, proposto reiteradamente: "Como articular os conceitos e pressupostos teóricos, vistos em sala de aula, e aplicá-los nas práticas vivenciadas cotidianamente em estágios ou ambientes de trabalho?".

De fato, já dizia um velho ditado que "na prática, a teoria é outra". Entretanto, na medida em que assumimos o papel de educadores, sentimo-nos constantemente inquietados por essa "provocação". Por meio desse relato, abordaremos algumas possíveis contribuições teórico-metodológicas da Psicologia Comunitária ao planejamento e execução de políticas sociais, apresentando um recorte da experiência de consultoria técnica em psicologia comunitária prestada à UNESCO, no âmbito do Programa de Prevenção da Violência do Estado do Rio 
Grande do Sul, no período compreendido de julho de 2009 a julho de 2010. Será discutido o processo de capacitação realizada junto a uma equipe de gestores públicos e técnicos de diferentes áreas (Segurança Pública, Saúde, Educação, Assistência Social, entre outros), com a finalidade de instrumentalizá-los para a elaboração de um Diagnostico Situacional da Violência e intervenção em uma comunidade com altos índices de vulnerabilidade.

\section{O Programa de Prevenção da Violência no Rio Grande do Sul}

A implementação de políticas de prevenção à violência - concebidas a partir do campo da saúde coletiva - tem se tornado uma importante estratégia de enfrentamento das "violências" que incidem sobre contextos comunitários vulneráveis. Cabe aqui salientar que, partindo dos fundamentos do paradigma ecológico contextual da psicologia comunitária (KELLY, 1992), preferimos a adoção do termo "violências" (no plural), em detrimento do termo "violência" (no singular), muito embora ambos os termos far-se-ão presentes ao longo desse texto. O plural salienta e melhor define o caráter multicausal desse fenômeno, que envolve aspectos desde um nível macrossocial ( fatores políticos, econômicos, culturais), até uma esfera microssocial (fatores biológicos, psicológicos, entre outros). Aproximamo-nos, assim, do conceito de violência estrutural proposto por Minayo e Souza (1997-1998, p. 8), segundo o qual a violência

se aplica tanto às estruturas organizadas e institucionalizadas da família como aos sistemas econômicos, culturais e políticos que conduzem à opressão de grupos, classes, nações e indivíduos, aos quais são negadas conquistas da sociedade, tornando-os mais vulneráveis que outros ao sofrimento e à morte.

Fato é que, no intuito de fazer frente aos impactos provocados pelas inúmeras situações de "violências", que incidem especialmente sobre as camadas mais vulneráveis da população, têm-se desenvolvido novos modelos de ação social pautados na valorização de ações em nível local, na participação e protagonismo de seus moradores, no investimento em capacitação e qualificação profissional das equipes que atuam nesses contextos. Também a efetivação de parcerias público-privadas, a participação ativa do terceiro setor (entenda-se a sociedade civil organizada), a autogestão e descentralização de ações, a criação de conselhos e comitês de gestão que possibilitem a participação ativa da comunidade, são algumas características marcantes desses novos modelos (GOMES et al., 2006).

Partindo do entendimento de que a violência, para além de um problema de segurança pública, constitui-se num problema de saúde pública, o Governo do Estado do Rio Grande do Sul lançou, no ano de 2007, o Programa de Prevenção da Violência (PPV). Sob a coordenação da Secretaria Estadual de Saúde e viabilizado pela criação da Câmara Setorial de Segurança e Prevenção da Violência e do Comitê Estadual para a Prevenção da Violência no Estado do Rio Grande do Sul (RIO GRANDE DO SUL, 2007a, 2007b), o PPV iniciou suas atividades propondo-se a realizar um trabalho de caráter preventivo, por meio da formação de uma rede social de atendimento às comunidades de maior vulnerabilidade social nos 50 municípios $^{2}$ com maiores índices de mortes por causas externas no Estado. Sua execução estruturou-se por meio de parcerias entre o governo do estado, prefeituras municipais, organizações não governamentais e membros das comunidades que passavam a integrar os chamados "Comitês de Prevenção à Violência”, tendo em vista a efetiva integração de ações de prevenção e promoção junto às comunidades com maior vulnerabilidade social.

No seu período inicial, ainda no ano de 2007, o PPV foi implantado em cinco municípios-piloto. A partir do ano de 2009, por meio da celebração de um Termo de Cooperação Técnica com a UNESCO, o Programa foi ampliado a outros 45 municípios, através do trabalho direto de consultoria prestada aos gestores municipais. A metodologia do trabalho de consultoria consistiu, entre outras atividades, no assessoramento ao chamado Grupo Técnico Gestor Municipal (GTGM), uma equipe composta por gestores públicos e técnicos de diferentes áreas (Segurança Pública, Saúde, Educação, Assistência Social, entre outros), com vistas à elaboração de um Diagnóstico Situacional da Violência no município e, posteriormente, de um Plano de Ação para o enfrentamento das situações de violência detectadas por meio do diagnóstico inicialmente realizado.

Nesse relato, apresentaremos apenas o "recorte" relativo ao processo de capacitação dos gestores para a elaboração do Diagnóstico Situacional da Violência junto à comunidade, processo esse que sob a perspectiva da psicologia comunitária pode ser considerado um processo de "intervenção psicossocial", ou seja, um tipo de intervenção "cujo foco e conteúdo são as relações interpessoais, a construção de redes de apoio, a coesão, as lideranças, as crenças, as representações sociais" (SARRIERA, 2009, p. 17).

\section{Fundamentos para Elaboração do Diagnóstico Situacional}

Um dos primeiros aspectos que devemos considerar ao iniciar um processo de intervenção em uma comunidade é que, seja qual for a ação ou atividade que se pretende realizar, é imprescindível um adequado planejamento, que nos permita estabelecer parâmetros claros para a ação, bem como objetivos e metas realísticos. Cabe salientar que este planejamento deve possuir, por um lado, sustentação teórico-conceitual e, por outro, conhecimento suficiente acerca da realidade dessa comunidade: sua história, seus costumes, seu cotidiano, evolução, cultura, etc. Assim sendo, uma das primeiras etapas de um planejamento visando à intervenção comunitária deve ser o levantamento e análise das necessidades ou diagnóstico situacional do problema específico a ser enfrentado. $\mathrm{O}$ processo de diagnóstico inicial em um contexto comunitário deve levar em conta os seguintes questionamentos: "Quais problemas (conflitos, dificuldades) afligem essa comunidade? Que necessidades são sentidas, percebidas,

\footnotetext{
${ }^{2} \mathrm{O}$ levantamento prévio dos 50 municípios inseridos no Programa se deu através de um estudo prévio, intitulado "Mapa social da violência: cartografias sociais dos crimes e das violências no Rio Grande do Sul" (TAVARES DOS SANTOS et al., 2009).
} 
inferidas por essa população? Quais recursos institucionais, pessoais, redes dispõem para a solução desses problemas e necessidades?" (SARRIERA, 2010, p. 142).

Tendo em vista a necessidade de capacitar a equipe de gestores e técnicos municipais para uma aproximação efetiva com a comunidade e para o levantamento dos indicadores de violência, desenvolveu-se uma proposta de caráter teórico-prático para a realização de um diagnóstico situacional da violência comunitária. Tal proposta teve como objetivo principal constituir-se num dispositivo de dupla função junto a essa equipe de gestores: um instrumento de aprendizagem, conhecimento e compreensão do fenômeno da violência comunitária e, ao mesmo tempo, um instrumento mobilizador para a ação. Em outras palavras: uma ferramenta que pudesse servir, para todos os efeitos, como um modelo descritivo da realidade complexa sobre a qual, posteriormente e em conjunto com a comunidade, seria elaborado o Plano de Ações específicas, voltadas a alterar as situações-problema.

Assim, antes mesmo de planejar o processo de assessoramento aos gestores, foi preciso eleger um enquadre teórico e conceitual que se mantivesse alinhado à metodologia do Programa e, ao mesmo tempo, aos valores éticos e de compromisso social, indispensáveis ao papel do psicólogo(a) comunitário(a). Um enquadre que permitisse, além disso, examinar, analisar, estabelecer relações e levantar hipóteses acerca dos problemas de violência presentes numa determinada comunidade. Optou-se pela adoção do Método de Planejamento Estratégico Situacional (PES), desenvolvido pelo economista chileno Carlos Matus (1997), segundo o qual o diagnóstico de uma situação é a base para a definição das ações em um plano estratégico ou de ação.

O diagnóstico situacional, segundo o Método PES, possui um enfoque participativo e eminentemente estratégico e, por conseguinte, se constitui na base essencial para a avaliação de um determinado quadro ou processo social (ESCOLA DE SAÚDE PÚBLICA DO RIO GRANDE DO SUL, 2008). Na medida em que se busca mesclar o conhecimento técnico ao compartilhamento social de informações e opiniões, a adoção desse método permite identificar, selecionar e conhecer em profundidade a situação problemática, bem como os recursos locais disponíveis para enfrentá-la. O elemento central do diagnóstico situacional, no âmbito desse Programa, foi a possibilidade de produção de um quadro que identificasse e relacionasse entre si os problemas mais relevantes relacionados à violência numa determinada comunidade.

No entanto, cabe salientar que, na concepção de gestão delineada por Matus (1997), o foco de uma ação estratégica implica em "planejar para construir viabilidade", mantendo a atenção sobre o que é mais importante fazer para atingir os objetivos traçados. Sendo assim, o planejamento eficaz do diagnóstico situacional torna-se parte imprescindível para a qualificada execução da ação. Também sob o ponto de vista da psicologia comunitária, entende-se que, a adoção de uma teoria adequa$\mathrm{da}$, aliada a uma metodologia que nos indique claramente objetivos e metas específicos a serem alcançados nos permite superar um dos entraves que historicamente tem dificultado a eficácia das intervenções em comunidades: a incoerência entre o pensar e o fazer, o uso frequente da "metodologia do ensaio-erro ou da intuição profissional" (SARRIERA 2010, p. 27), vícios que acabaram por transformar muitas das práticas comunitárias em ações de caráter meramente assistencialista.

Entendemos, assim como Huertas (1996), que a realidade não é passível de ser explicada por meio de uma simples descrição ou diagnóstico, mas por diferentes interpretações fornecidas pelos atores sociais envolvidos: a "apreciação situacional" emitida pelos moradores da comunidade. Lembramos que o termo situacional provém do conceito de "situação", que, sob o ponto de vista dessa perspectiva, exige determinar quem está explicando a realidade, uma vez que a realidade é passível de ser explicada de diferentes formas, dependendo dos diferentes propósitos dos atores nela implicados (MATUS, 1998).

\section{Levantamento e Análise de Dados sobre Violência Comunitária}

Segundo Rolim (2008), embora o Brasil seja considerado "um país sabidamente violento", os dados disponíveis acerca das manifestações da violência no país são quase sempre precários, incompletos ou mesmo inconfiáveis. E o que é ainda pior: na medida em que o país não dispõe ainda de um serviço nacional de pesquisas de vitimização, segue produzindo (e reproduzindo) diagnósticos baseados quase que única e exclusivamente em tendências criminais e práticas violentas, a partir dos dados registrados em boletins de ocorrência policial. Tal prática, na medida em que desconsidera as amplas taxas de subnotificação da violência, termina por promover uma imagem no mínimo equivocada a respeito do problema da violência, destacando apenas algumas de suas manifestações e mantendo outras sob completa invisibilidade. Outro problema, segundo o autor, refere-se ao fato de que as próprias informações coletadas pelas diferentes agências do sistema de segurança pública integram bases de dados que não dialogam entre si e que, portanto, não dispõem de critérios mínimos de padronização.

Trabalhar a partir do conceito de "violências" constitui-se, portanto, num enorme desafio, posta a amplitude e dificuldade de sua conceituação e delimitação. A própria Organização Mundial de Saúde (2002, p. 1), utilizando-se de um conceito bastante amplo, tem definido violência como,

o uso deliberado da força física ou do poder, seja em grau de ameaça ou de forma efetiva, contra si próprio, outra pessoa, um grupo ou comunidade, que cause ou tenha probabilidade de causar lesões, morte, danos psicológicos, transtornos ao desenvolvimento pessoal e social ou privações do atendimento às necessidades.

Compartilhando da opinião de que indicadores de violência não se reduzem unicamente a taxas de homicídios ou boletins de ocorrências policiais e que, suas manifestações são multifacetadas e atravessam inúmeras relações sociais, tornou-se necessário, no contexto da intervenção aqui descrita, estabelecer junto ao gru- 
po de gestores "outro paradigma" para a produção do diagnóstico sobre a violência; paradigma esse capaz de superar o viés focado única e exclusivamente em dados da área de segurança pública.

Freitas (1998) reitera que o tipo, a extensão, o compromisso da intervenção realizada são delineados pela forma ou maneira como se dá o processo de inserção na comunidade. Nesse sentido, ressalva-se a importância da associação de métodos quantitativos e qualitativos na elaboração do diagnóstico, bem como de inserções que privilegiem a participação da comunidade na busca pela produção de conhecimentos "em conjunto". Foi a partir dessas premissas, que o modelo de diagnóstico a partir do qual o grupo de gestores foi capacitado, constituiu-se de duas etapas: um levantamento quantitativo, a partir da coleta e análise de dados estatísticos acerca de notificações diversas de situações de violência (dados oriundos do sistema hospitalar, educacional, policial, de trânsito e mobilidade urbana, entre outros); e um levantamento de caráter qualitativo, realizado a partir da coleta de informações junto à comunidade local. Cabe ressaltar que por meio da etapa qualitativa buscou-se estimular a aproximação e familiarização dos gestores com o contexto da comunidade e seus moradores, valorizando o processo dialógico e a mútua aprendizagem e - ao mesmo tempo - explicitando o crucial papel a ser exercido pelos membros da comunidade tanto na condição de informantes das características contextuais como, principalmente, no que se refere ao seu protagonismo no processo de transformação social.

\section{Processo de Capacitação: Descrição da Proposta Teórico-Metodológica}

A capacitação pode ser entendida como um processo que visa, essencialmente, fortalecer grupos de profissionais para que possam construir, em seu cotidiano de trabalho, ações conjuntas para a resolução de problemas e transformações almejadas. Consiste em uma ação organizada, direcionada e permanente de exercício da capacidade de compreensão do outro, por meio da prática do diálogo genuíno e da reflexão sobre a própria prática. São momentos propícios para "esclarecer, acolher, sensibilizar e envolver as equipes", e por isso, entende-se que "quanto maior o envolvimento das equipes no processo de formação, maior será seu comprometimento com a ação em busca da transformação", tendo em vista que "mudar envolve rever a cultura, os valores, os hábitos e as rotinas previamente estabelecidas" (NOLETO, 2008, p. 65).

O processo de capacitação desenvolveu-se através de duas reuniões semanais, com três horas de duração, na qual participaram 12 membros do Grupo Técnico Gestor Municipal (GTGM), formado por secretários municipais e técnicos das áreas da Saúde, Segurança, Educação e Desporto, além de representantes do Conselho de Municipal de Segurança, do Departamento de Proteção Social Básica, Secretaria de Mobilidade Urbana, da Coordenadoria da Mulher, do Programa Primeira Infância Melhor e do Conselho Municipal de Entorpecentes (COMEN) de um município gaúcho. ${ }^{3}$

${ }^{3}$ Por questões éticas, o nome do município, da comunidade, assim como dos profissionais envolvidos no processo de capacitação serão mantidos em sigilo.
Os principais objetivos dessa ação foram: orientar os gestores quanto aos meios e fontes disponíveis para o levantamento de dados e registros de violência acerca da comunidade; instrumentalizar os profissionais para a intervenção comunitária, tendo em vista a construção conjunta do diagnóstico situacional da violência; desenvolver discussões acerca da problemática da violência; desmistificar preconceitos e representações negativas acerca dos moradores de comunidades vulneráveis; estimular a operacionalização de uma rede municipal voltada à prevenção da violência. Ao final de cada encontro, foram disponibilizados aos gestores formulários de avaliação por meio do qual se buscou identificar o grau de satisfação com as atividades desenvolvidas, bem como avaliar possíveis impactos gerados nas percepções acerca do problema da violência comunitária, e, consequentemente, nas ações a serem implementadas em contexto comunitário.

\section{Procedimentos}

\section{$1^{\circ}$ Etapa: Levantamento de Dados Quantitativos}

Nessa etapa buscou-se instrumentalizar os participantes, em nível teórico-prático, para a construção do Diagnóstico Situacional da Violência, a partir do Método de Planejamento Estratégico Situacional (PES) e pressupostos e técnicas oriundos da psicologia comunitária.

Os mesmos foram orientados sobre como e onde ${ }^{1}$ coletarem dados referentes à caracterização geral da comunidade (indicadores socioeconômicos e demográficos, Índice de Desenvolvimento Humano da localidade, população residente por faixa etária, renda familiar per capita, entre outros); indicadores de educação (média de anos de estudo, taxa de evasão, distorção série, idade, etc.); mapeamento da rede de serviços e projetos existentes (referente às áreas da saúde, educação, segurança, assistência social, defesa de direitos, etc.); panorama dos acidentes e registros de violência (a partir de bancos de dados da saúde, segurança, trânsito, conselhos municipais, etc.).

Além disso, como forma de sensibilizar e integrar o grupo para o efetivo trabalho em equipe, foi utilizada uma técnica dinâmico-grupal: a dinâmica dos rótulos (MILITÃO, A.; MILITÃO, R., 2002). Solicitou-se aos membros do grupo que discutissem durante dez minutos sobre a seguinte questão: "Qual a solução para o problema da violência comunitária?”. Ao final do tempo estabelecido, o grupo deveria apresentar três propostas concretas de solução para esse problema. Essa discussão, no entanto, deveria ser realizada de acordo com "o rótulo" (insígnia) que cada profissional portava, através de uma etiqueta adesiva colada sobre a cabeça. Foram previamente preparadas etiquetas com expressões como: "concorde comigo", "sou perigoso", "agrida-me", "ignore-me", "sou mentiroso", entre outras.

Ao longo da atividade percebeu-se que, ainda que o grupo tenha se proposto a cumprir a tarefa inicial de apresentar propostas de solução para o problema da violência comunitária, a discussão centrou-se nos rótulos que cada um portava, tornando a discussão satirizada e hostil em determinados momentos. Ao término da dinâ-

Fractal, Rev. Psicol., v. 27 - n. 2, p. 145-151, 2015 
mica, os participantes puderam verificar suas respectivas insígnias e expor suas percepções e sentimentos. Um dos aspectos mais relevantes mencionado pelos participantes referiu-se a dificuldade de trabalhar em um grupo no qual os membros se encontram previamente "rotulados". Salientou-se ainda que, o fato de "rotular" as comunidades ou seus moradores como violentos ou perigosos, poderia impedir a observação de suas reais características e potencialidades, dificultando assim a elaboração de um diagnóstico adequado acerca do problema. Nesse sentido, cabe ressaltar que a problematização de leituras estigmatizantes dos contextos comunitários e a busca por consolidar políticas assentadas na noção de direitos sociais são consideradas compromissos fundamentais dos profissionais da Psicologia Comunitária (XIMENES; PAULA; BARROS, 2009). Sendo assim, aproveitando os sentimentos e as percepções propiciados por essa dinâmica, salientou-se a importância do comprometimento de cada profissional e da equipe como um todo, em prol do desenvolvimento comunitário.

\section{$2^{a}$ Etapa: Levantamento de Dados Qualitativos (Oficina de Definição de Demandas, junto à comunidade).}

Nesta etapa da capacitação, os gestores foram instrumentalizados para realizar, junto à comunidade, uma Oficina de Definição de Demandas. Tal oficina teria por objetivo informar a comunidade acerca do programa a ser implementado, intensificar sua participação no processo de definição de demandas, além de conhecer os modos como estes atores sociais interpretavam e significavam a sua realidade, no que se referia especificamente aos problemas relativos à violência. Tal experiência produziu implicações significativas também na etapa subsequente do processo, na qual foi elaborado - em conjunto com a comunidade um plano de ação para o enfrentamento da violência.

Propôs-se, para tanto, a realização de um chamamento local, com vista à realização do encontro com moradores da comunidade-alvo. Para a realização desta oficina, os gestores foram capacitados para a realização de três atividades junto aos membros da comunidade:

\section{Atividade 1: "Quem conta um conto, aumenta um ponto".}

Essa atividade tinha por objetivo proceder ao levantamento de histórias da comunidade, promovendo-se uma espécie de "gincana" através da qual os participantes, divididos em duas ou mais equipes, relatavam fatos e histórias significativas acerca das situações de violências na comunidade.

\section{Atividade 2: Que comunidade temos?}

Nessa etapa, o objetivo era promover um amplo debate com os membros da comunidade sobre diversos aspectos da historia local, depoimentos sobre projetos, programas, equipamentos esportivos e culturais existentes.

\section{Atividade 3: Que comunidade queremos?}

Por fim, essa atividade objetivou discutir e elencar as necessidades dos diversos grupos que integravam a comunidade referente ao enfrentamento da violência e melhoria do bem-estar e qualidade de vida local. Para tanto, sugeriu-se a divisão entre os diferentes segmentos presentes: grupos de jovens, idosos, mulheres, entre outros.

\section{Considerações finais}

A trajetória da Psicologia nas políticas sociais e comunitárias tem se caracterizado, nos últimos 25 anos, pela transformação de um trabalho anteriormente rotulado "psicoterapia para os pobres" em ações de assistência e saúde pública com foco em saúde mental na atenção básica, na prevenção e promoção à saúde, na educação popular, diminuição da violência, e demais problemas relacionados a quadros de pobreza extrema (YAMAMOTO; OLIVEIRA, 2010).

A capacitação para a construção do Diagnóstico Situacional Comunitário, aqui descrita, constituiu-se num espaço de ação/reflexão acerca do papel social de gestores e técnicos no âmbito de um Programa cujo escopo era bastante amplo e que visava, entre outras metas, estabelecer práticas de prevenção à violência por meio do fortalecimento e empoderamento comunitário, mapeando as potencialidades e vulnerabilidades desses contextos. Cabe lembrar que o termo empoderamento (empowerment), remete ao aumento do poder e da autonomia pessoal e coletiva de indivíduos e grupos sociais nas relações interpessoais e institucionais, principalmente daqueles submetidos às relações de opressão, discriminação e dominação social. Trabalhos que buscam o empoderamento local contribuem para o surgimento de um tecido social fortalecido pelas interações que promovem e essencialmente conferem "poder" aos atores sociais envolvidos (VASCONCELOS, 2004). Segundo considerações apresentadas por Montero (2010), é por meio do processo de fortalecimento comunitário (que ocorre através da discussão e reflexão sobre os problemas, a capacitação para a organização, a participação, liderança, entre outros processos) que seus membros desenvolvem as capacidades e recursos imprescindíveis para que possam efetivamente assumir o controle sobre suas próprias circunstâncias.

Os resultados demonstraram (tendo como base os formulários de avaliação respondidos pelos participantes) que os encontros de capacitação contribuíram para a construção de um olhar mais crítico e menos estigmatizado desses profissionais acerca do problema da violência comunitária. A partir do trabalho e reflexão conjunta entre gestores de diferentes setores (segurança, saúde, educação, entre outros) tornou-se possível à identificação dos múltiplos e complexos fatores implicados no problema da violência comunitária, permitindo assim uma visão mais holística e, por consequência, menos segmentada por parte destes profissionais. Para além do simples levantamento de indicadores e análises de estatísticas policiais, significou a possibilidade de examinar, analisar, estabelecer relações e levantar hipóteses acerca das 
inúmeras formas de "violências" presentes na comunidade, visando o fortalecimento das redes sociais de modo a atuar como uma ferramenta de proteção e prevenção.

Por meio deste relato, buscamos discutir alguns aspectos teórico-práticos que subsidiaram uma experiência de trabalho desenvolvida na intersecção entre os campos das políticas sociais e da psicologia comunitária. A sistematização do processo de capacitação desenvolvido com a equipe de gestores nos permite, ao mesmo tempo, conceitualizar nossa prática e colocar "em sistema" o nosso fazer. Segundo Holliday (2006), na medida em que reconstruímos nossa prática, por meio de relatos sistematizados, reordenamos e objetivamos o processo vivido e convertermos nossa própria experiência em objeto de estudo e interpretação teórica e, ao mesmo tempo, em objeto de transformação.

Sob nosso ponto de vista, a articulação entre teoria e prática - percebida muitas vezes como entrave, dificuldade ou mesmo desafio por parte de alunos e profissionais constitui-se num dos pilares fundamentais da psicologia comunitária, tanto no que se refere à execução de projetos e políticas publicas, quanto ao fortalecimento comunitário. É exatamente esse "dogma do distanciamento" que precisa ser superado a fim de que nossas ações e intervenções possam tornar-se cada vez mais efetivas e eficazes.

Por fim, entendemos que o conhecimento teórico é uma condição necessária, e fundamental, porém não suficiente para produzir as transformações tão almejadas por profissionais e estudantes que adentram o campo das políticas públicas e sociais. Em se tratando da complexidade dos problemas a serem enfrentados no dia-a-dia das comunidades, dos serviços de assistência ou de saúde que atuamos, torna-se indispensável à adoção de uma práxis

transformadora e ajustada a objetivos. Fora dela fica a atividade teórica que não se materializa, na medida em que é atividade espiritual pura. Mas, por outro lado não há práxis como atividade puramente material, isto é, sem a produção de finalidades e conhecimentos que caracteriza a atividade teórica (VAZQUEZ, 1968, p. 108).

É, portanto, um desafio para todos nós - profissionais, educandos e educadores - a proposição de estratégias que minimizem o distanciamento entre o planejamento e a execução de intervenções comunitárias. Acreditamos que sistematizar experiências e compartilhar com os pares nossas estratégias de intervenção constitui-se num importante passo para reduzir esse aparente distanciamento entre aquilo que "aprendemos" e aquilo que "fazemos", entre o que "planejamos" e o que efetivamente "realizamos" em nosso cotidiano de trabalho.

\section{Referências}

ESCOLA DE SAÚDE PÚBLICA DO RIO GRANDE DO SUL. Plano Operativo do Programa de Prevenção da Violência. Porto Alegre, ESP/RS, 2008.

FREITAS, M. F. Q. Inserção na comunidade e análise de necessidades: reflexões sobre a prática do psicólogo. Psicologia Reflexão e Crítica, Porto Alegre, v. 11, n. 1, p. 175-189, mar./ abr. 1998.

GOMES, R. et al. Êxitos e limites na prevenção da violência: estudo de caso de nove experiências brasileiras. Ciência \& Saúde Coletiva, Rio de Janeiro, v. 11, n. 2, 2006. p. $397-$ 408. Disponível em: <http://dx.doi.org/10.1590/S141381232006000500018>. Acesso em: 7 mar. 2012

HOLlidAY, O. J. Para sistematizar experiências. 2. ed. Brasília: MMA, 2006.

HUERTAS, F. Entrevista com Matus. São Paulo: FUNDAP, 1996.

KELLY, J. G. et al. Psicologia comunitária: el enfoque ecológico contextualista. Buenos Aires: Centro Editor de América Latina, 1992.

MATUS, C. Adeus, senhor presidente: governantes governados. São Paulo: FUNDAP, 1997.

MATUS, C. Teoria de la produción y el juego social. Isla Negra: Altadir, 1998.

MILITÃO, A.; MILITÃO, R. Jogos, dinâmicas \& vivencias grupais: como desenvolver sua melhor "técnica" em atividades grupais. Rio de Janeiro: Qualitymark, 2002.

MINAYO, M. C. de S.; SOUZA, E. R. Violência e saúde como um campo interdisciplinar e de ação coletiva. História, Ciências, Saúde - Manguinhos, Rio de Janeiro, v. IV, n. 3, p. 513-531, nov. 1997 - fev. 1998.

MONTERO, M. A Tensão entre o fortalecimento e as influências alienadoras no trabalho psicossocial comunitário e político. In: GUZZO, R. S. L.; LACERDA JR., F. (Org.). Psicologia e Sociedade: interfaces no debate da questão social. Campinas, SP: Alínea, 2010. p. 65-81.

NOLETO, M. J. Fortalecendo competências: formação continuada para o Programa Abrindo Espaços: educação e cultura para a paz. Brasília: UNESCO/Fundação Vale, 2008.

ORGANIZACIÓN MUNDIAL DE LA SALUD. Informe mundial sobre la violencia y la salud: resumen. Washington, DC: OMS, 2002.

RIO GRANDE DO SUL. Assembleia Legislativa do Estado do Rio Grande do Sul. Decreto $n^{\circ} 44.907$, de 27 de fevereiro de 2007. Cria a Câmara Setorial de Segurança e Prevenção da Violência e dá outras providências. 2007a. Disponível em: < http://www.al.rs.gov.br/Legis/M010/M0100099.ASP?Hid_ Tipo $=$ TEXTO\&Hid_TodasNormas $=50460 \& \mathrm{hTexto}=\&$ Hid IDNorma=50460>. Acesso em: 14 jul. 2011.

RIO GRANDE DO SUL. Assembleia Legislativa do Estado do Rio Grande do Sul. Decreto $n^{\circ} 44.908$, de 27 de fevereiro de 2007. Institui o Comitê Estadual para a Prevenção da Violência no Estado do Rio Grande do Sul. 2007b. Disponível em: < http://www.al.rs.gov.br/legis/M010/M0100099.ASP?Hid Tipo=TEXTO\&Hid_TodasNormas $=50461 \&$ hTexto $=\& H i d$ IDNorma=50461>. Acesso em: 14 jul. 2011. 
ROLIM, M. Mais educação, menos violência: caminhos inovadores do programa de abertura das escolas públicas nos fins de semana. Brasília: UNESCO/Fundação Vale, 2008.

SARRIERA, J. C. A intervenção social: suas origens, aspectos éticos, conceituais e metodológicos. In: CENCI, C. M. B.; MAURINA, L. R. C.; WAGNER, M. F. (Org.). Intervenções da psicologia: transitando em diferentes contextos. Passo Fundo: IMED, 2009. p. 13-24.

SARRIERA, J. C. Análise de necessidades de um grupo ou comunidade: avaliação como processo. In: SARRIERA, J. C.; SAFORCADA, E. T. (Org.). Introdução à Psicologia Comunitária: bases teóricas e metodológicas. Porto Alegre: Sulina, 2010. p. 141-154.

TAVARES DOS SANTOS, J. V. et al. Mapa social da violência: cartografias sociais dos crimes e das violências no Rio Grande do Sul. Rio Grande do Sul: UFRGS, 2009. Relatório de Pesquisa.

VASCONCELOS, E. O poder que brota da dor e da opressão: empowerment, sua história, teorias e estratégias. Rio de Janeiro: Paulus, 2004.

VAZQUEZ, A. S. Filosofia da práxis. Rio de Janeiro: Paz e Terra, 1968.

XIMENES, V. M.; PAUlA, L. R. C.; BARROS, J. P. P. Psicologia Comunitária e Política de Assistência Social: diálogos sobre atuação em comunidades. Psicologia Ciência e Profissão, Brasília, v. 29, n. 4, p. 686-699, out./dez. 2009.

YAMAMOTO, O. H; OLIVEIRA, I. F. Política social e psicologia: uma trajetória de 25 anos. Psic: Teor. e Pesq. Brasília, v. 26, n. spe, p. 9-24, 2010. Disponível em: <http:/ dx.doi.org/10.1590/S0102-37722010000500002>. Acesso em: 20 abr. 2012.

Recebido em: 3 de maio de 2012

Aceito em: 28 de janeiro de 2015 